\title{
Nontraumatic Pure Acute Subdural Hematoma Caused by a Ruptured Cortical Middle Cerebral Artery Aneurysm: Case Report and Literature Review
}

\author{
Kentaro Awaji, ${ }^{1}$ Ryota Inokuchi, ${ }^{1}$ Ritsuko Ikeda, ${ }^{2}$ and Toshihiko Haisa ${ }^{2}$
}

\begin{abstract}
Nontraumatic or "spontaneous" acute subdural hematoma (SDH) is rare, and "pure" acute SDH without subarachnoid hemorrhage (SAH) due to aneurysmal rupture is extremely rare. We report a case of nontraumatic pure acute SDH caused by the rupture of a cortical middle cerebral artery (MCA) aneurysm. A 43-year-old man with no antecedents, except hypertension, presented to the emergency department with acute-onset moderate headache and nausea after swimming. He reported neither preceding head trauma nor dental check-up. Neurological examinations and laboratory tests were unremarkable. Computed tomography (CT) showed an acute SDH on the left convexity without $\mathrm{SAH}$, but both magnetic resonance (MR) angiography and three-dimensional CT (3D-CT) angiography disclosed no vascular abnormality. As he became drowsy, the patient emergently underwent an evacuation of the SDH. Unexpectedly, a small saccular aneurysm of a cortical branch of the left MCA was recognized at surgery. Although indocyanine green (ICG) angiography revealed this aneurysm was thrombosed, a clip was applied on the aneurysmal base. He was discharged home without any complications 21 days after admission. To seek the cause of nontraumatic acute SDH, supplementary examinations including 3D-CT, MR, and/or catheter angiography are necessary. Even if angiography reveals no vascular lesions, the present case warrants that the cortical surface should be meticulously inspected at surgery, because a thrombosed cortical artery aneurysm might be an underlying cause.
\end{abstract}

Keywords: acute subdural hematoma, cerebral aneurysm, middle cerebral artery

\section{Introduction}

The majority of acute subdural hematoma (SDH) occur due to head trauma, and nontraumatic or "spontaneous" acute SDH is rare, which is caused by various etiologies such as cortical artery bleeding, vascular lesions, coagulopathy, neoplasms, spontaneous intracranial hypotension, cocaine, and arachnoid cyst. ${ }^{1,2)}$

We report an exceedingly rare case of nontraumatic "pure" acute SDH without SAH, which was caused by rupture of a thrombosed aneurysm of a cortical branch of the left middle

Departments of Emergency Medicine ${ }^{1}$ and Neurosurgery, ${ }^{2}$ JR Tokyo General Hospital, Shibuya, Tokyo

Received: June 10, 2015; Accepted: November 28, 2015 cerebral artery (MCA). The necessity of angiographic examinations is emphasized, and the management of such patients is briefly discussed.

\section{Case Report}

A 43-year-old man with no antecedents, except hypertension, developed headache around the temples, nausea, and vertigo when he got out of a swimming pool after diving down about $1 \mathrm{~m}$ deep. He was brought to the emergency room by ambulance, since his headache and nausea got worse and he vomited. He reported neither preceding head trauma nor dental check-up.

On examination, his vital signs were as follows: body temperature, $35.4^{\circ} \mathrm{C}$; pulse rate, 65 beats $/ \mathrm{min}$; and blood pressure, 152/109 mmHg. Neurological examinations were unremarkable, and the results of laboratory tests were within normal limits. He was considered to have developed headache because of hypoxia caused by diving down in a pool. Acetaminophen was prescribed and he was monitored on the bed in the emergency room. As his headache recurred after transient improvement and he began vomiting again, computed tomography (CT) of the head was taken 3 hours after his presentation, which disclosed an acute SDH on the left convexity (Fig. 1). Brain magnetic resonance (MR) and three-dimensional CT (3D-CT) angiography showed no vascular abnormality. On the ground that MR imaging showed expansion of the SDH and that his consciousness level deteriorated, the patient was emergently taken to the operating room and underwent a left-sided craniotomy. When the hematoma was removed, a small bulging of a cortical branch of the left MCA came into view, unexpectedly. Under an operating microscope, this was recognized as a saccular aneurysm, $1.5 \mathrm{~mm}$ in diameter, and the tip of its reddish dome was in the epiarachnoid space (Fig. 2A, arrow). Adhesion between the aneurysm and the arachnoid was not evident. Although indocyanine green (ICG) angiography revealed this aneurysm was thrombosed (Fig. 2B), a clip was applied on the aneurysmal base. Successful clipping was confirmed by ICG angiography (Fig. 2C). On the basis of the operative findings, he was finally diagnosed as having had an acute SDH caused by rupture of a cortical MCA aneurysm.

The postoperative course was uneventful with no echocardiographic or serologic evidence of infective endocarditis, and cerebral angiography revealed no vascular abnormalities (Fig. 3). He was discharged home without any complications 21 days after admission. At the 1-year follow-up, he was doing well. 


\section{Discussion}

Nontraumatic or "spontaneous" acute SDH is rare, accounting for $0.7-6.7 \%$ out of all acute SDHs. ${ }^{3)}$ According to the review of 193 cases collected by Coombs et al., ${ }^{2}$ its etiology included cortical artery bleeding, vascular lesions, coagulopathy, neoplasms, spontaneous intracranial hypotension, cocaine, and arachnoid cyst. Considering that its mortality was as high as $37.2 \%,{ }^{2)}$ accurate diagnosis of the underlying cause and appropriate treatment are crucial.

With regard to aneurysmal rupture, this most often leads to subarachnoid hemorrhage (SAH) with or without intracerebral and/or intraventricular hemorrhage. On the other hand, aneurysmal SDH with or without SAH is rare, the incidence

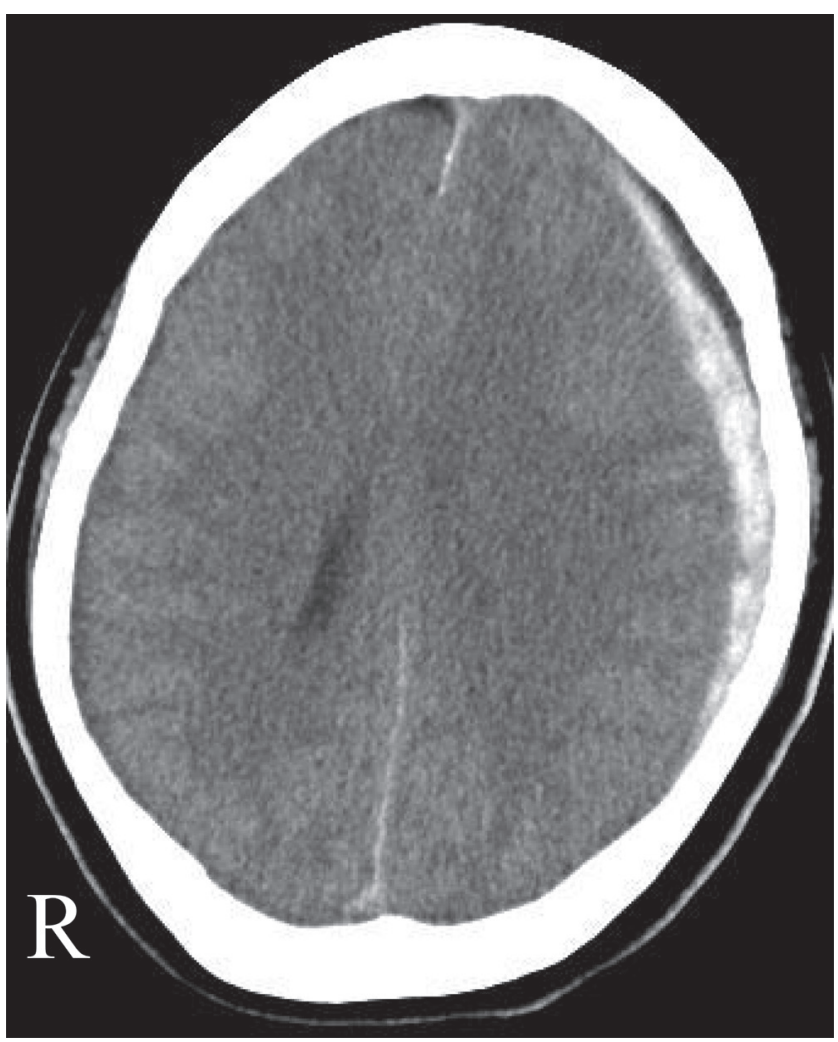

Fig. 1 Axial computed tomography scan of the head showing a subdural hematoma on the left convexity. of which was estimated to be between $0.5 \%$ and $7.9 \%{ }^{4}$ ) Pure acute SDH without SAH secondary to aneurysmal rupture is especially rare. Takada et al. ${ }^{5)}$ and Gong et al. ${ }^{6)}$ reviewed 29 and 41 such cases, respectively. According to their study, internal carotid-posterior communicating artery aneurysm was the most frequent, accounting for approximately $50 \%$, and cortical MCA aneurysm was less common., ${ }^{5,6)}$ We could collect no more than eight cases of pure acute SDH due to cortical MCA aneurysm in the literature, including the present case (Table 1). ${ }^{6-12)}$ In this article, we excluded cases of cortical MCA aneurysm related to head trauma. ${ }^{13)}$ It is no surprise that aneurysmal rupture could tear the arachnoid and form SDH without SAH, if the arachnoid on the rupture point is very thin, especially in case there is adhesion between a cortical aneurysm and the arachnoid. From the viewpoint of ruptured aneurysm sites, the cortical segment of the MCA is extremely rare. According to the series reviewed by Horiuchi et al., ${ }^{14)}$ there was only one cortical MCA aneurysm out of 2,788 patients with surgically treated ruptured aneurysms. This was an infectious aneurysm secondary to infective endocarditis. The pathogenesis of distal MCA aneurysms include infectious or neoplastic emboli, head trauma, arteritis, and arterial dissection. ${ }^{15)}$ At least, the present patient did not have infection, inflammation, neoplasms, or head trauma.

The management of acute SDH needs prompt decisionmaking. In case of nontraumatic acute SDH, it is necessary to seek the causes, especially vascular lesions. ${ }^{16)}$ Supplementary neuroimaging examinations include 3D-CT, MR, and catheter angiography. Although digital subtraction catheter angiography is the gold standard for detection of cerebrovascular lesions, less time-consuming 3D-CT or MR angiography should be chosen alternatively for patients in poor neurological condition. In life-threatening cases, whether traumatic or not, emergency decompression surgery should be performed. In patients with nontraumatic acute SDH, however, immediate postoperative angiography is recommended, because a causative aneurysm may be detected like the case 4 described by Nozar et al. ${ }^{4}$ The present case is very interesting in that a thrombosed aneurysm, nonvisualized on 3D-CT and MR angiograms, was an underlying cause. To our knowledge, only one similar case has been reported: a 57-year-old man with nontraumatic pure acute SDH was
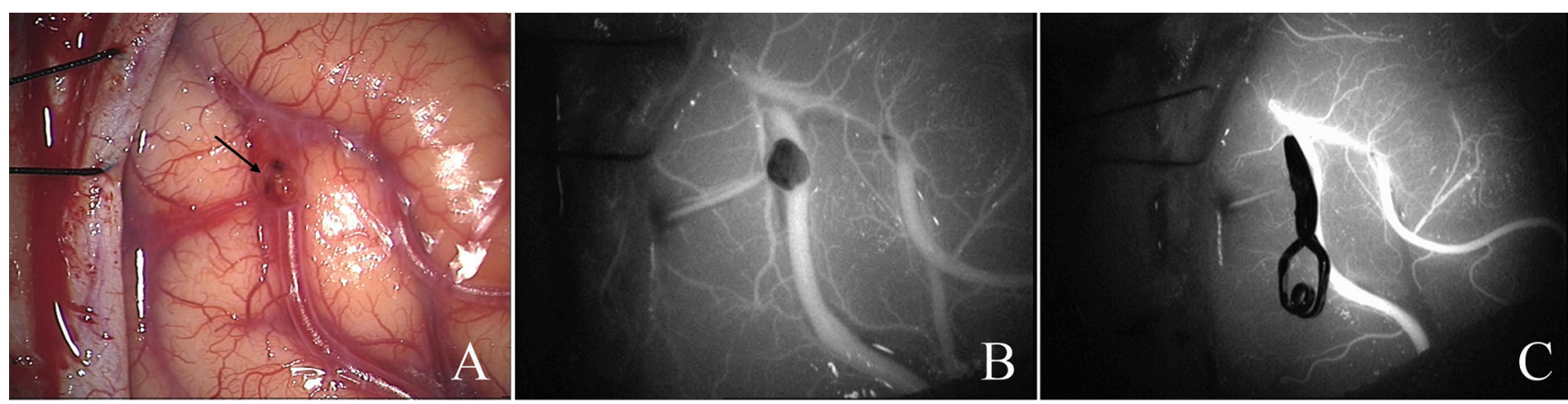

Fig. 2 A: Intraoperative photograph demonstrating a saccular aneurysm of a cortical branch of the left middle cerebral artery (arrow). B: Indocyanine green (ICG) angiography showing the aneurysm is thrombosed. C: ICG angiography showing the aneurysm is successfully clipped. 


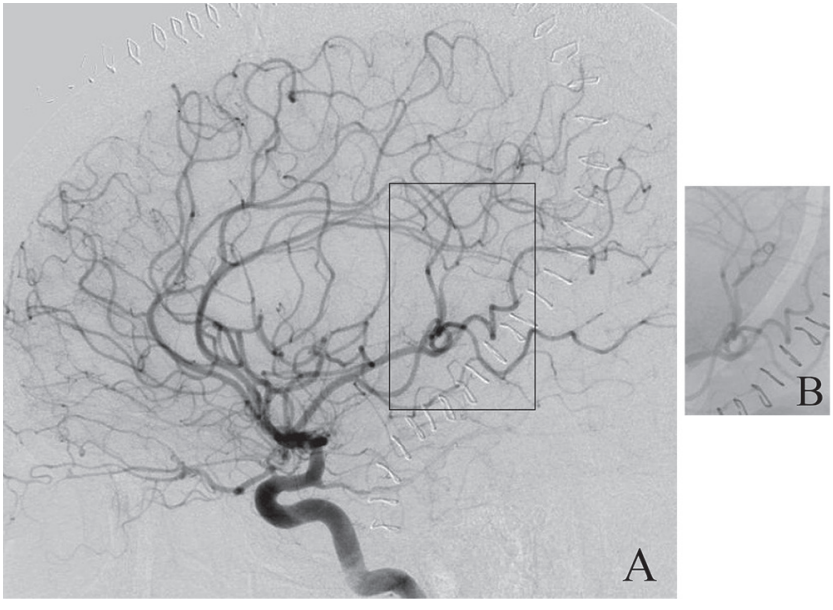

Fig. 3 Postoperative left internal carotid angiograms, lateral view. A: Digital subtraction angiogram revealing no vascular abnormalities. B: Digital angiogram of the square area showing the clip.

Table 1 Cases of nontraumatic pure acute subdural hematoma caused by cortical middle cerebral artery anerurysm

\begin{tabular}{|c|c|c|c|}
\hline $\begin{array}{l}\text { Author } \\
\text { (Year) }\end{array}$ & $\begin{array}{l}\text { Age }(y r s) / \\
\text { Sex }\end{array}$ & Angiography treatment & Outcome \\
\hline $\begin{array}{l}\text { King } \\
(1960)^{7)}\end{array}$ & $23 / \mathrm{F}$ & $\begin{array}{l}\text { Carotid arteriography demonstrated } \\
\text { an aneurysm. Hematoma removal } \\
\text { and aneurysm excision were done } \\
\text { simultaneously. }\end{array}$ & good \\
\hline $\begin{array}{l}\text { Boop et al. } \\
(1961)^{8)}\end{array}$ & $37 / \mathrm{M}$ & $\begin{array}{l}\text { Carotid angiography revealed an } \\
\text { aneurysm. Hematoma evacuation, } \\
\text { neck clipping, and dome excision } \\
\text { were done simultaneously. }\end{array}$ & good \\
\hline $\begin{array}{l}\text { Rengachary } \\
\text { and } \\
\text { Szymanski } \\
(1981)^{9)}\end{array}$ & $49 / \mathrm{M}$ & $\begin{array}{l}\text { A postoperative arteriography } \\
\text { showed a } 4 \times 3 \mathrm{~mm} \text {-aneurysm. } \\
\text { Aneurysm clipping and excision } \\
\text { were done } 6 \text { weeks after hematoma } \\
\text { evacuation. }\end{array}$ & good \\
\hline $\begin{array}{l}\text { Hori et al. } \\
(2005)^{10)}\end{array}$ & $57 / \mathrm{M}$ & $\begin{array}{l}\text { DSA showed no vascular anomaly. } \\
\text { Hematoma evacuation and neck } \\
\text { clipping were done simultaneously. }\end{array}$ & good \\
\hline $\begin{array}{l}\text { Kurabe et al. } \\
(2010)^{11)}\end{array}$ & $75 / \mathrm{M}$ & $\begin{array}{l}\text { DSA revealed an aneurysm. } \\
\text { Hematoma evacuation and aneurysm } \\
\text { resection were done simultaneously. }\end{array}$ & n.d. \\
\hline $\begin{array}{l}\text { Gong et al. } \\
(2014)^{6)}\end{array}$ & $43 / \mathrm{M}$ & $\begin{array}{l}\text { DSA showed an aneurysm. } \\
\text { Hematoma evacuation and aneurysm } \\
\text { resection were done simultaneously. }\end{array}$ & good \\
\hline $\begin{array}{l}\text { Singla et al. } \\
(2014)^{12)}\end{array}$ & $25 / \mathrm{F}$ & $\begin{array}{l}\text { DSA revealed an aneurysm. } \\
\text { Hematoma removal and neck } \\
\text { clipping were done simultaneously. }\end{array}$ & good \\
\hline Present case & $43 / \mathrm{M}$ & $\begin{array}{l}\text { MR and 3D-CT angiography showed } \\
\text { no vascular abnormality. } \\
\text { Hematoma removal and neck } \\
\text { clipping were done simultaneously. }\end{array}$ & good \\
\hline
\end{tabular}

3D-CT: three-dimensional computed tomography, DSA: digital subtraction angiography, F: female, M: male, MR: magnetic resonance. n.d.: not described. operated on, and a ruptured cortical MCA aneurysm, nonvisualized on preoperative cerebral angiograms, was found at surgery and clipped. Therefore, neurosurgeons should bear in mind the possibility that angiographically nonvisualized aneurysm might be a causative lesion of acute SDH.

Although the mechanism of acute and spontaneous intraaneurysmal thrombosis is uncertain, we speculate that it might have been produced by intra-aneurysmal blood stagnation secondary to compression of the aneurysm by the surrounding $\mathrm{SDH}$, and that intravenous administration of epsilon-aminocaproic acid might have played some role. It is known that a thrombosed or angiographically undetectable aneurysm could appear on follow-up angiograms and rebleed. ${ }^{17,18)}$ This is the reason we decided to obliterate the thrombosed aneurysm. As the present aneurysm was thought to be neither traumatic nor infectious and clipping was actually feasible, we chose to clip its base instead of trapping or resection.

In conclusion, in patients with nontraumatic pure acute $\mathrm{SDH}$, thorough investigations including 3D-CT, MR, and/or catheter angiography are mandatory to seek for the cause of bleeding. Even if angiography reveals no vascular lesion in such cases, the cortex should be meticulously inspected at surgery, because a thrombosed cortical artery aneurysm might be found.

\section{Conflicts of Interest Disclosure}

The authors have no disclosure to report. The authors have no personal, financial, or institutional interest in any of the drugs, materials, or devices in the article. All authors who are members of The Japan Neurosurgical Society (JNS) have registered online Self-reported COI Disclosure Statement Forms through the website for JNS members.

\section{References}

1) Talalla A, McKissock W: Acute "spontaneous" subdural hemorrhage. An unusual form of cerebrovascular accident. Neurology 21: 19-25, 1971

2) Coombs JB, Combs BL, Chin EJ: Acute spontaneous subdural hematoma in a middle-aged adult: case report and review of the literature. J Emerg Med 47: e63-e68, 2014

3) Komatsu Y, Uemura K, Yasuda S, Shibata T, Kobayashi E, Maki Y, Nose T: [Acute subdural hemorrhage of arterial origin: report of three cases]. No Shinkei Geka 25: 841-845, 1997

4) Nozar A, Philippe D, Fabrice P, Silvia M, Marc T: Acute pure spontaneous subdural haematoma from ruptured intracranial aneurysms. Interv Neuroradiol 8: 393-398, 2002 (Japanese)

5) Takada T, Yamamoto T, Ishikawa E, Zaboronok A, Kujiraoka Y, Akutsu H, Ihara S, Nakai K, Matsumura A: Acute subdural hematoma without subarachnoid hemorrhage caused by ruptured A1-A2 junction aneurysm. Case report. Neurol Med Chir (Tokyo) 52: 430-434, 2012

6) Gong J, Sun H, Shi XY, Liu WX, Shen Z: Pure subdural haematoma caused by rupture of middle cerebral artery aneurysm: Case report and literature review. J Int Med Res 42: 870-878, 2014

7) King AB: Successful surgical treatment of an intracranial mycotic aneurysm complicated by a subdural hematoma. J Neurosurg 17: 788791, 1960

8) Boop WC, Chou SN, French LA: Ruptured intracranial aneurysm complicated by subdural hematoma. J Neurosurg 18: 834-836, 1961

9) Rengachary SS, Szymanski DC: Subdural hematomas of arterial origin. Neurosurgery 8: 166-172, 1981

10) Hori E, Ogiichi T, Hayashi N, Kuwayama N, Endo S: Case report: acute subdural hematoma due to angiographically unvisualized ruptured aneurysm. Surg Neurol 64: 144-146, 2005 
11) Kurabe $S$, Ozawa $T$, Fujiwara $H$, Watanabe $T$, Aiba T: Peripheral intracranial aneurysm causing subdural hematoma without subarachnoid hemorrhage. Neurology 74: 268, 2010

12) Singla N, Tripathi M, Chhabra R: M5 segment aneurysm presenting as "pure acute SDH". J Neurosci Rural Pract 5: 402-404, 2014

13) Cho WS, Batchuluun B, Lee SJ, Kang HS, Kim JE: Recurrent subdural hematoma from a pseudoaneurysm at the cortical branch of the middle cerebral artery after mild head injury: case report. Neurol Med Chir (Tokyo) 51: 217-221, 2011

14) Horiuchi T, Tanaka Y, Takasawa H, Murata T, Yako T, Hongo K: Ruptured distal middle cerebral artery aneurysm. J Neurosurg 100: 384 388,2004

15) Nussbaum ES, Madison MT, Goddard JK, Lassig JP, Nussbaum LA:
Peripheral intracranial aneurysms: management challenges in 60 consecutive cases. J Neurosurg 110: 7-13, 2009

16) De Blasi R, Salvati A, Renna M, Chiumarulo L: Pure subdural hematoma due to cerebral aneurysmal rupture: an often delayed diagnosis. Cardiovasc Intervent Radiol 33: 870-873, 2010

17) Nakajima Y, Yoshimine T, Mori H, Nakamuta K, Fujimura I, Sakashita K, Kohmura E, Hayakawa T, Yokota J: Spontaneous disappearance and reappearance of a ruptured cerebral aneurysm: one case found in a group of 33 consecutive patients with subarachnoid hemorrhage who underwent repeat angiography. Neurol Res 22: 583-587, 2000

18) Chohan MO, Westhout FD, Taylor CL: Delayed rebleeding of a spontaneously thrombosed aneurysm after subarachnoid hemorrhage. Surg Neurol Int 5: 42, 2014

Corresponding author:

Toshihiko Haisa, MD, PhD, Department of Neurosurgery, JR Tokyo General Hospital, 2-1-3 Yoyogi, Shibuya, Tokyo 151-8528, Japan.

$\checkmark$ haisat-kkr@umin.ac.jp 